\title{
Sustainable urban food districts (SUFD): Strategical spatial planning in urban food systems. An analysis to the Toronto food strategy policy
}

\author{
Sebastian Felipe Burgos Guerrero* \\ Sustainable Territorial Development, KU Leuven, Belgium
}

\begin{abstract}
The recognition of a historical absence on urban food systems analysis by the academia, incentivized new discussion on planners and food activist only over the past 15 years. The predominant belief on food as an agricultural and rural issue, has fostered its detachment from the urban agenda, filling the gap with predominant market driven strategies. This paper aims to provide a comprehensive vision on the food system organization in urban areas, analysing the need to integrate it into a broader urban strategy and strategical spatial planning. The challenges and opportunities it portrays the need to consolidate competitive and sustainable solutions for an increasing urban population and their connected social challenges. Thus, comprehended into a broader spectrum of issues of public concern such as health, social justice, economic prosperity, social cohesion, food security, culture, waste management and ecological integrity. The paper includes the analysis of a case study, the Toronto Food Strategy as a recognition of the role urban planners could play to forge policies towards more sustainable food systems.
\end{abstract}

\section{Introduction}

The population growth predicted by 2050 for about 9 billion people, underpins enormous challenges for the satisfaction of adequate food consumption. The growing productivity brought by the introduction of new technologies and intensive agricultural practices, supported a threefold increase on the food production over the past 50 years [1]. Nevertheless, a limited access to food for vulnerable groups and an increasing food waste are still part of this reality. For the period of 2010 to 2012 estimations registered almost 870 million people, about 12.5 percent of the world's population, being under nourished and around 1 billion malnourished [1]. This converges in opposition to the paradigmatic rise of obesity and cardiovascular diseases, due to unhealthy dietary patterns, as main concerns for the public health. A clear dilemma is underlined, increasing food supplies and limited or inadequate food consumption patterns at our current global food system. The inadequate access to food is therefore one of the main pillars of this challenging global perspective, determining physical, economic and social constraints, where poverty continue to be a main driver of social injustice and nutritional inequality [2-4]. In addition to these phenomena, scholars continue to reveal the ecological impacts of current food systems, with agricultural challenges, but not only, setting ground on water deficits, water, soils and air pollution, impoverishment of soil fertility, GHG emissions and deprived ecological systems at the core of the environmental global discussion concerning urban growth [5].

In $2014,54 \%$ of the world's population was living in urban areas, with projected estimations to increase by 2050 to $66 \%$ [6]. The growing urbanized world constitutes in this way a main leader for the discussion of food systems, setting the cities as key players on future sustainable solutions for the environmental, social and economic global and local challenges. In 1999, Kameshwari Pothukuchi and Jerome L. Kaufman
[7] acknowledged the separation and invisibility of the food system to planning and urban policy officials, considered an agricultural issue grounded in rural settings and a stranger to planning research [8]. This coincides with a growing urbanization movement that saw the progressive disappearance of local farms and a reduced and more distant position of food in the urban systems, with a growing control exerted by corporate organizations [7]. A renewed interest of planners, policy makers, entrepreneurs and civil society over the past 20 years has intersect into a shared vision on the need to materialize sustainable solutions, revealing in food a growing topic of research and policy making [9-15].

This paper aims to shed light on the possible interconnections presented for urban planning to forge sustainable urban systems, in the integration of food systems analysis in the urban agenda and planning research. This followed a guiding question, can food be a cross cutting issue for planning research to consolidate sustainable urban systems in the broader public concerns? The research foresees a brief compilation of "the state of art" of the three main pillar concepts, Urban Food Systems, Urban Food Planning and Sustainability. A multidisciplinary research will be implemented, gathering information from different fields of study with related literature on urban and regional planning, applied geography, urban research, food system analysis, Social Innovation, Economic development, Rural Sociology and Food Policy. Finally, all the information will be analyzed and critically assessed on the specific

${ }^{\star}$ Correspondence to: Sebastian Felipe Burgos Guerrero, Master Student in Sustainable Territorial Development, KU Leuven, Belgium, E-mail: sebastianfelipe.burgosguerrero@student.kuleuven.be

Key words: food policy, urban food planning, sustainable food systems, strategical spatial planning

Received: May 17, 2019; Accepted: June 05, 2019; Published: June 10, 2019 
Case Study of the city of Toronto, The Toronto Food Strategy, comparing the current urban food policy and future opportunities, to set the food system analysis at the table of planners and urban policy makers.

\section{Conceptual framework}

\section{Urban food systems analysis}

To understand the dynamics of Food and its different interactions in urban settings, a systemic approach in a multi-dimensional and comprehensive perspective is required. The Food system is an interdisciplinary study object, with a multifunctional character that sets a vision on multiple interconnections with the public health, the local economy, land use organization, distribution and transportation systems, agricultural land preservation, ecological integrity, solid waste management, food security and overall quality of life [10-12]. The food security, seen in the past essentially on a productive perspective, is now identified on its physical, social and economic limitations, whereby vulnerable populations fail in accessing to affordable and healthy foods [7].

The analysis of urban food systems leads us therefore to the interrelated character of its different subsystems, conceptualized on the food cycle chain: production, transformation, processing, distribution, consumption, waste disposal, and the interconnections that each of those encompass on the aforementioned public concerns $[5,10,14,16]$. The vision has effectively been assimilated by corporate organizations, setting a vertical integration model as core of their business structure and planning strategies, represented in Agro-parks, vertical farms and other institutional organizations, allowing them to exert control on the whole process from the farm to the dish.

Three main interrelated systems in the urban foodscape have been identified: 1) The dominant conventional food system, as main provider of food for cities, represented in food stores, wholesalers and agribusiness corporate organizations. 2) The emergency food systems in the form of food banks, food pantries and soup kitchens, as a private and public cooperation to alleviate major failures of the previous mentioned system, in benefit of the poor and vulnerable groups of the population. In parallel to these two, the alternative food systems (AFS) emerged as a reactionary movement to loosed connections of local farmers and city consumers, viewed as a re-territorialisation process of a so called "co-producer' dynamic form of cooperatives, farmers markets and community supported agriculture farms with a strong emphasis on environmental sustainable food production, local and community bonds $[17,18]$. The latter, aggregates an emergent group, the so-called community food security movement, bridging conventional channels with sustainable agriculture communities $[8,10,12,18]$. It is in this foodscape, where a complex net of power relations is forged, creating a strong concentration of players with dominant relations from the conventional food systems in the form of corporate organizations, with a clear and predominant globalized and monopolistic character. The urban food system is in this context situated at a passive position, acting mainly as a main center of consumption in a globalized flow of distribution, alienated from other forms of production and social organization $[7,8]$. The dependent position of urban areas to the global food circulation, demonstrated to be threatening, as a "new food equation" formula [10]. The latter took form during the food crisis of 2007/2008, where global major crop price increases, left national food security of cities in doubt. This combined to poor geographic, economicand disproportioned environmental and nutritional inequalities, adding major pressure to urban policy makers. The convergence of these elements resulted in renewed attention and awareness of social leaders and society to strength the call for a sustainable 'local' urban food systems as a key condition for a renewed urban agenda $[10,19]$.

\section{Urban food planning}

Despite what has been agreed so far, food has not been only an issue of modern research. In 1946, Ebenezer Howard discussed what he denominated the New Garden cities, as a vision of marriage between town and country, in the form of a green belt, appropriately located and efficiently served by transport systems, to integrate the circular food system approach, of production, distribution, consumption and recycling into the design of urban systems [19]. In conjunction to Howard's proposition, Walter P. Hedden shed light in 1929 on his work How great cities are Fed, the enormous physical and economic challenges that cities had to overcome as to ensure the appropriate distribution and consumption of food, highlighting the functional role of municipal food terminals as part of the urban planning [20].

The quest for sustainable solutions in the current complex dynamics of urban food systems raised an emerging movement of planners, with new interpretations and interest on the broader multidimensional possibilities of food to contribute in rendering cities more sustainable with respect to its social, economic and ecological effects. In 2009, Morgan defined food planners as "anyone who is working in, or engaged with, the food system with the aim of rendering it more sustainable" agreeing this to be one of the most important social movements of the early twentyfirst century in the global north [19]. The previous mentioned barriers described by Pothukuchi and Kaufman in the early 2000's, as not being well integrated to planning issues, is based on the political dichotomy of rural and urban domain, the limited economic and institutional support, the monopolistic role of the private sector and the general acceptance of these forces [8]; seem today to be overcome and under development [10]. In 2007, the American Planning Association issued a White Paper introducing food in the planning agenda, equal to other sectors, such as housing, transport, energy and green spaces. Contemporaneously, the Association of European Schools of Planning established its first Food Planning Working Group in 2009, bringing together a diverse range of backgrounds from different fields, be they planners, policy- makers, politicians, designers, farmers, civil society, and others, engaged in rendering the food system more sustainable (AESOP, 2017). Other to the academic momentum experienced in the last years for the food systems research, food started to be also a main driver of political action in the form of guidelines, policies, programs and planning strategies at the national, regional and urban level. The goal of improving citizens' health, small farmers' ability to stay in business, and cities' climate resilience, has brought a global empathy to food policies and strategies [10]. Cities all over the world have embraced food on its urban plans, represented in the emblematic case of London [21], Amsterdam (AMS' Network for Sustainable Food Planning, ANFP), Utrecht [19], Toronto [22] or Belo Horizonte, "the city that ended hunger" [19]. The reconnection of food to the cities emerges in parallel to the so- called Food policy councils, already over 100 in the U.S., supporting the implementation of broader goals on public health, economic development, social justice and sustainability through the lens of food. Carolyn Steel on her book Hungry city emphasized this potential, which "viewed laterally, emerges as something with phenomenal power to transform not just landscapes, but political structures, public spaces, social relationships, cities" [23]. Among other things, food policies have served as effective institutional tools to bridge sectors, visions and actions in common strategies and alliances. Thus, creating a knowledge pool of information and good practices for both researches and local actors. Planners as such, are 
contributing in collecting, compiling and analyzing data, relevant for decision making, interconnecting food with other planning sectors and assessing their impacts into current food planning strategies. They also contribute on the dissemination of good practices, education of future planners and their integration into sustainable values and food issues in the planning agenda [8].

The case study presented at the end of this papers, the Toronto food Strategy Policy, will shed light on these experiences, providing key factors, tools and methodological opportunities for planners and urban decision makers to effectively integrate food in future research and urban policies. The paper emphasizes on the opportunities of a conceptual model, so called Sustainable Urban Food Districts (SUFD) as a sustainable cluster for the materialization of alliances and synergism in a common food strategy towards sustainable urban food systems.

"When considering the relation between cities and food, we tend to think about it as the sole matter of choosing the best way to feed cities and ignore the social, cultural, and environmental opportunities that systems unsuited for ensuring steady and abundant influx of food in cities can yield. If cities are to play a pivotal role in tackling the challenge of sustainable development, this mindset will need to change. The emergent realm of urban food planning is one domain of practices that opens up new spaces to do so" [10].

\section{Urban food districts, towards sustainable urban food systems}

Kevin Morgan condensed with these words the importance and challenges of sustainable food systems in cities:

Feeding the city in a sustainable fashion - that is to say, in way that is economically efficient, socially just and ecologically sound - is one of the quintessential challenges of the twenty-first century and it will not be met without a greater political commitment to urban food planning and a bolder vision for the city [11].

The food planning movement needs to embrace a cosmopolitan conception of sustainability in which alternative re- territorialized local food systems could merge with a broader global and supra-local level into a balanced parity of esteem, avoiding what Morgan agrees to be a new "social movement (...) degenerated into a parochial form of green localism" [11]. One example is given by Morgan, linking how the American food planners' association surpassed the limitations of localism through the creation of a national network, the Community Food Security Coalition, giving to each single local food movement a national recognition, support and representation [11].

However, continuing with Morgan's proposition, sustainability cannot be reduced to a carbon metric parameter, linked to local or global food production, but it should embrace both social and economic as well as environmental dimensions. Suggesting more focus on the social realm, where a moral obligation has still to be re-emphasized to the poor and hungry of the world, neglected in the current food system [11].

The spatial analysis of urban systems, as may be the food, can be of valuable contribution for this ambition. One of the challenges of a spatial approach to food dynamics is the understanding of territorial cohesion. The synergic relations created by the integration of different actors and subsystems, may be of important contribution for the broader urban social, economic and environmental development process. This should be grounded on the spatial analysis of the urban foodscapes, using planning tools and analysis methods to reveal relevant information and characteristics that drive strategic spatial configurations. These could be represented in the form of urban agriculture initiatives, land use schemes, transportation systems and logistics, Community food security assessments [24], food transformation and processing systems, distribution channels, spatial mapping on the access to food in form of stores and farmers markets [2], food consumption and dietary behaviors and effective waste management cycle systems, among others $[8,10,12,14,16,25,26]$. As such, we found great opportunities for sustainability in the spatial planning research on food systems, identifying possible opportunities in geographical organizations of socalled food clusters or food districts. The Food cluster, in this view is a space where different levels of exogenous and endogenous initiatives and networks come into play [27].

The basic dynamics of food and innovative districts lay in the proximity of elements, facilities, resources and activities. This offers advantages for food production, whereby customers, human resources, costs, risks and benefits can be shared and supported. A geographic concentration offers advantageous conditions for synergism and networking between different initiatives, activities and stakeholders [27]. The organization of 'urban food districts 'can play in this view an important role in the strategic urban planning on food systems, enhancing the role of food in the local economy, supporting innovation and creativity in small farmers and citizens, enhancing the sense of belonging and social integration and coping with the ecological integrity of a changing climate and renewed landscape urbanisms.

Physical and functional networks improve the business opportunities and the community cooperation, for the development of inter- or intra- sectoral strategic alliances [27]. The food district discloses valuable opportunities with several benefits, mainly in terms of food security, social innovation, community building, social integration and as a medium for urban regeneration and competitive economic development, in the consolidation of sustainable urban systems $[2,8,10,14,16,18,24,26]$. Food clusters could be described as functional and innovative hubs in networking stakeholders, at a geographic core area for the materialization of sustainable urban food systems [27]. The SUFD's encompass strong partnerships and alliances between different systems and actors, unifying same interests into synergies for sustainable food production, efficient and re-territorialized distribution systems, innovative and traditional transformation processes, healthy and cultural appropriate food diets and waste management cycles, on a social, cultural, economic and environmental territorial perspective.

The more the food system is being dominated by global forces, the greater the value to re-emphasize the uniqueness of territories, the differences between places, regions and cultural distinctiveness of communities [27]. The re-localization of the food system has been widely discussed by scholars [10,14,16-18,24,26,28], agreeing on the definition of local food as a re-territorialized system of relations, cooperation and sustainable alternatives for cities $[10,14,18]$. This vision is well represented in the so called integrated territorial food geography concept (Figure 1) described by Johannes Wiskerke as a territorial and integrated modus of food governance, linking different public domains and policy objectives (Government, Market and Civil Society) to contribute in sustainable regional development [14,29].

Nevertheless, it is important to keep the discussion in the current global context, encompassed in the dominant role of international corporations, which need to be re-configured rather than entirely replaced into this territorial perspective [10]. This paper argues that a middle way is possible, whereby planning research may intersect the major opportunities to bring the food issue back to the urban agenda and set a collective and participative discussion on the consolidation 


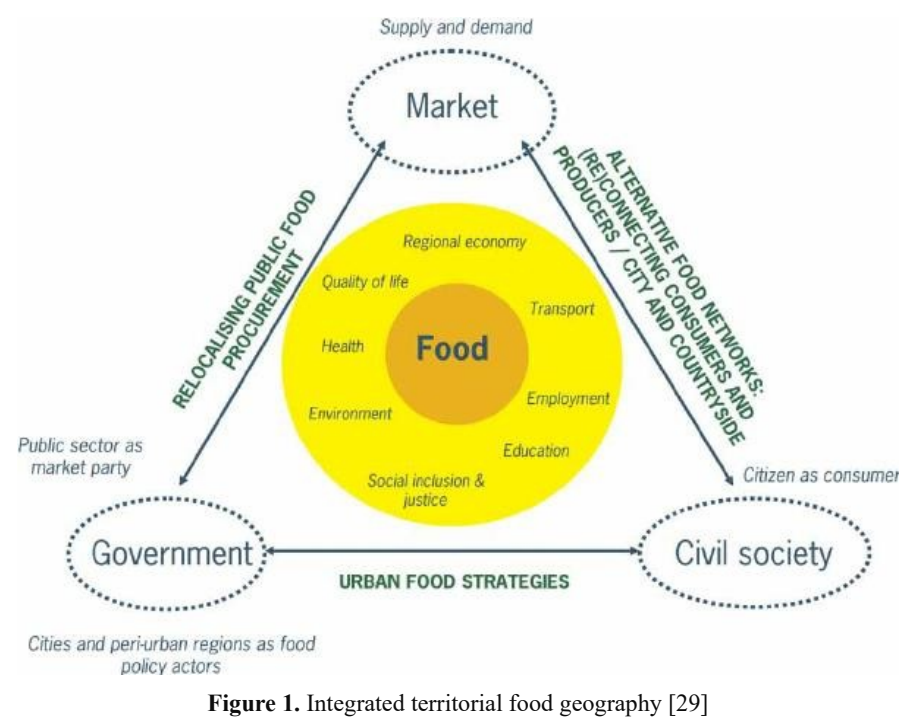

of sustainability in the urban systems $[18,26]$. Their success will depend on the effective capacity of planners and decision makers to build such alliances, serving themselves of food as a common agent for creating strong partnerships, beyond sectoral or institutional boundaries [19]. The Sustainable Urban Food District (SUFD), could bridge these opportunities, clustering different actors and networks in strategic alliances that re- enforces the role of food in the city, providing synergism and spatial spheres between the different dominant systems at the pair of small and emergent ones, to engage them all in joint initiatives, activities and policies of a common food strategy.

\section{The Toronto food strategy policy case study}

The Toronto Food Strategy will guide the research on the understanding of challenges, barriers and dynamics that beard in the urban food governance process. The research has been restricted to the available literature, city plans and policy recommendations since the early attempts of the city to bring such initiative to the urban agenda in 2007. The short analysis will provide us a clear vision on the opportunities for SUFD's to integrate and materialize such strategies in the strategical planning of cities and urban food geographies [29].

\section{The Toronto food strategy}

In spring 2008, the Toronto board of health endorsed the initiative for the development of the first Food Strategy in the city. The rapid acceptability of the proposal resulted on the assignation of Pieter Dorfman as responsible for the development of the Strategy [22]. In May 2010, the introduction of the Toronto Food Strategy, Cultivating Food Connections: Toward a Healthy and sustainable Food System for Toronto, was achieved. Stating in the initial report of 2010, to be "more than just a report or set of recommendations but (...) the ongoing process of identifying, building and strengthening positive connections - between local government and residents, among City Divisions, within the community, and with the countryside (...) about the future of Toronto's food and creative initiatives that are flourishing across the city" [30].

The strategy was built on the positive achievements undertaken in the past by the Toronto Food Policy council, established in 1990 [31], and the Toronto Public Health on issues such as the lack of economic security of local food producers, the high levels of food waste, the inequalities on healthy food access, the growing rates of obesity and chronic diseases and the environmental threats of intensive food production and climate change, of a growing and highly diverse city with over 5.5 million inhabitants as in the great area of Toronto [32]. Striking issues as poverty and health inequality, became main drivers for the local government to see in food a meaningful vehicle for intersectoral action and policy change [30].

The strategy set the basis for cooperation, opening a deliberative and innovative space for mutual construction of meaning [33], forge alliances and create synergism among the different food stakeholders in an inclusive discussion toward a healthy and sustainable food system [30]. The group succeeded to become a bridge between the municipality and local communities, engaged on the formation of local networks and active citizenship as incubators for policy innovations, partnership creation and social change. With this aim, the strategy identified six main guiding objectives: the elimination of hunger, food as a centrepiece of the new green economy, food friendly neighbourhoods, empowered residents with food skills and information, a connected city and country-side through food and an embedded food system thinking in city government $[22,30]$.

In this way, food became a main instrument for the action of a healthy, sustainable and prosperous city. The strategy created a propitious environment that set the food system thinking at the table of planners and policy makers, bridging horizontal management strategies and collaborations among governmental divisions, while addressing broader social constraints in connection to an active citizenship. This enable all municipal divisions and civil society to work together, setting a latent urban governance mechanism that made food visible in the urban political agenda [31].

Some strategical initiatives were undertaken for this period, we would like to focus on three of them, relevant for the scope of this research: The food access mapping, the community food skills and employability pilot project and the Community kitchen food hubs. The former is described as a geographical mapping of the city for the identification and data collection of the Toronto foodscape [34]. The initiative reveals main geographic gaps on the accessibility and availability of healthy and affordable foods and provided main social indicators in connection to space on the local and regional food production [22]. The instrument provided key information to decision makers for the effective and appropriate implementation of researchbased solutions. Some of these resulted in the strategical distribution of mobile vending trucks, flexible transit transfers and participatory actions at the neighbourhood level [35]. 2) The community food skills and employability pilot project, provided skill formation and institutional support in form of food literacy programs and food safety training to marginalized communities [30]. The initiative in cooperation with other agents of the city, materialized economic opportunities for citizens, setting a certification scheme that allowed participants to be more competitive in their search for jobs in the food sector [22]. 3) The community kitchen policy initiative, provided common spaces for interaction and social engagement around food. The initiative connects different communities together in "food hubs", as incubator spaces [10] in form of supportive neighborhoods, using kitchens as ground spaces for intercultural interaction, social integration and innovation [36].

As we saw, the Toronto food strategy succeeded to be an effective mediator between the local municipality and an active citizenship and created relevant partnerships among society for common objectives. The strategy, used food not as a political objective per se, food as policy, but as an enabler of broader social change, food for policy. The strategy helps to define possible boundaries and opportunities for food systems analysis and planning research to draw sustainable paths for the urban 
governance of food systems, identified in three planning tools: GIS for the collection of data on foodscapes [2], Community food security assessments [24] and incubator rooms [10], in form of the so called "food hubs". These are relevant examples of possible contributions that planning practices could forge in the effective and appropriate implementation of actions toward sustainable urban food systems [3740].

\section{Conclusions}

This paper provided an overall review on the opportunities that food systems analysis in conjunction with planning thinking could forge towards the construction of sustainable urban systems. An emblematic example, the Toronto Food strategy, helped us to define the major challenges and dynamics that food leading strategies could bring to the urban governance systems, setting food as an effective vehicle for intersectoral cooperation, horizontal management and active citizenship, into a food for policy vision. The proposed Sustainable Urban Food Districts model, provides further insights in possible planning systems to materialize such strategies into real actions and cooperation schemes where the urban governance could be implemented more effectively. This need to be based on the spatial analysis and complex understanding of socio-spatial dynamics, encompassed in the strategical spatial planning research. In this view, the SUFD's aims to stimulate further research on this field of study and contribute to the collective goal to bring sustainable solutions to our current urban food system.

\section{References}

1. FAO (2015) Statistical pocketbook. World food and agriculture. FAO, Rome

2. Eckert J, Shetty S (2011) Food systems, planning and quantifying access: Using GIS to plan for food retail. Applied Geography 31: 1216-1223.

3. Morgan K (2014) Nourishing the city: The rise of the urban food question in the Global North. Urban Studies 52: 1379-1394.

4. Marsden T, Morley A (2014) Sustainable food systems. Building a new paradigm. Edited by Routledge, Taylor \& Francis Group, pp: 240.

5. Oria M (2015) A Framework for assessing effects of the food system. Washington, National academies press.

6. United nations, department of economic and social affairs, population division (2014) World urbanization prospects: The 2014 revision, highlights (ST/ESA/SER.A/352).

7. Pothukuchi K, Kaufman J (1999) Placing the food system on the urban agenda: the role of municipal institutions in food systems planning. Agriculture and Human Values 16: 213-224.

8. Pothukuchi K, Kaufman J (2000) The food system. Journal of the American Planning Association 66: 113-124.

9. Ilieva R (2016) Urban food planning: Seeds of transition in the global north (Routledge studies in food, society and the environment) Milton: Taylor and Francis.

10. Ilieva R (2016) Urban food systems strategies: A New tool for implementing the SDGs in Practice? International conference on sustainable development (ICSD), September 2016.

11. Morgan K (2013) The rise of urban food planning. International Planning Studies 18: $1-4$

12. Brinkley C (2013) Avenues into food planning: A review of scholarly food system research. International Planning Studies 18: 243-266.

13. Pettenati G, Toldo A (2015) Introduction to special book review issue: giving food its space. Reflections about food planning and urban food systems. Urban Research \& Practice 8: 371-373.

14. Viljoen A, Wiskerke Johannes SC (2012) Sustainable food planning: Evolving theory and practice. Wageningen: Wageningen Academic, The Netherlands.

15. Mendes W, Nasr J, Beatley T, Born B, Bouris K, et al. (2011) Preparing future food system planning professionals and scholars: Reflections on teaching experiences. Journal of Agriculture, Food Systems, and Community Development 2: 15-52.
16. Hammer J (2004) Community food systems and planning curricula. Journal of Planning Education and Research 23: 424-434.

17. Agrillo C, Milano S, Roveglia P, Scaffidi C (2015) Slow food's contribution to the debate on the sustainability of the food system. $148^{\text {th }}$ seminar on does Europe need a food policy? Brussels, Belgium.

18. Broekhof S, Van der Valk A (2012) Planning and the quest for sustainable food systems: explorations of unknown territory in planning research. Sustainable food planning: Evolving theory and practice. Wageningen Academic Publishers, The Netherlands, pp: 393-404.

19. Morgan K (2009) Feeding the City: The challenge of urban food planning. International Planning Studies 14: 341-348.

20. Knapp J (1930) Article. The Journal of business of the university of Chicago 3: 263266.

21. Reynolds B (2009) Feeding a world city: The London food strategy. International Planning Studies 14: 417-424.

22. Mah C, Thang H (2013) Cultivating food connections: The Toronto food strategy and municipal deliberation on food. International Planning Studies 18: 96-111.

23. Steel C (2008) Hungry city: How food shapes our lives. London: Chatto \& Windus.

24. Pothukuchi K (2004) Community food assessment: A first step in planning for community food security. Journal of Planning Education and Research 23: 356-377.

25. Tornaghi C (2013) Critical geography of urban agriculture. Progress in Human Geography 38: 551-567.

26. Campbell M (2004) Building a common table: The role for planning in community food systems. Journal of Planning Education and Research 23: 341-355.

27. Jansen-Verbeke M (2007) Cultural resources and the tourism identification of territories. Acta Turistica Nova 1: 21-41.

28. Mansfield B, Mendes W (2013) Municipal Food strategies and integrated approaches to urban agriculture: Exploring three cases from the global north. International Planning Studies 18: 37-60.

29. Wiskerke Johannes SC (2009) On places lost and places regained: Reflections on the alternative food geography and sustainable regional development. International Planning Studies 14: 369-387.

30. Toronto public health (2010) Cultivating food connections: Towards a healthy and sustainable food system for Toronto.

31. Toronto food policy council (1999) Feeding the city from the back 40: A commercia food production plan for the city of Toronto, A section of the Toronto food policy council's submission to the city of Toronto's official plan.

32. Blay-Palmer A (2009) The Canadian pioneer: The genesis of urban food policy in Toronto. International Planning Studies 14: 401-416.

33. Mah C (2012) Local food policy in Canada and the next 20 years of the Toronto food policy council: An interview with Lauren Baker. The Journal of Canadian Food Cultures 3.

34. Toronto public health (2013) Bring food home: Food access mapping.

35. Toronto public health (2016) Toronto food strategy: 2016 update.

36. Fridman J, Lenters L (2013) Kitchen as food hub: adaptive food systems governance in the City of Toronto. Local Environment 18: 543-556.

37. Brimblecombe J, van den Boogaard C, Wood B, Liberato S, Brown J, et al. (2015) Development of the good food planning tool: A food system approach to food security in indigenous Australian remote communities. Health \& Place 34: 54-62.

38. Carsjens GJ (2015) Food in space: The spatial organization of food systems. Agric Eng Int.

39. Food smart cities for development. Recommendations and good practices. October 2015

40. Haugum M, Grande J (2017) The role of marketing in local food networks. Int J Food System Dynamics 8: 1-13.

Copyright: (C)2019 Guerrero SFB. This is an open-access article distributed under the terms of the Creative Commons Attribution License, which permits unrestricted use, distribution, and reproduction in any medium, provided the original author and source are credited. 